\title{
Organizações internacionais como agentes de transferência e difusão de políticas públicas
}

International organizations as public policy transfer and dissemination agents

Glaucia Julião Bernardo ${ }^{1}$

\section{RESUMO}

As organizações internacionais destacam-se no cenário mundial, direcionando e mediando o relacionamento entre países. Entretanto, é fundamental, também, discutir o impacto delas em âmbito interno. Pretende-se, neste artigo, demonstrar como as organizações internacionais podem condicionar as políticas públicas dos países. Com base nas teorias de transferência e difusão de políticas públicas, foram analisadas ações da ONU, do Banco Mundial, da UE e do Mercosul. Encontraram-se elementos que comprovam que esses atores podem ser agentes de transferência e difusão de políticas públicas.

Palavras-chave: organizações internacionais; transferência e difusão de políticas públicas.

\begin{abstract}
International organizations stand out in the world arena, directing and mediating the relationship between countries. However, it is also essential to discuss their impact inside the countries. The aim of this article is to demonstrate how international organizations can condition the public policies of the countries. Based on public policy transfer and dissemination theories, UN, World Bank, EU and MERCOSUR actions were analyzed. Elements found imply that these actors can be public policy transfer and dissemination agents.
\end{abstract}

Key-words: International organizations; Public policy transfer and dissemination.

1 Doutoranda em Políticas Públicas, UFPR, Curitiba, Brasil. 


\section{Introdução}

0 presente artigo pretende analisar a atuação das organizações internacionais como agentes de transferência e difusão de políticas públicas. Acredita-se que essas instituições podem influenciar as políticas de países-membros. Essa capacidade também pode ser observada em relação àqueles países que não aderiram ao tratado constitutivo. Sendo assim, justifica-se este estudo pela necessidade de entendimento de como se dá esse processo.

As organizações internacionais podem ser definidas como "associações voluntárias de Estados estabelecidas por acordo internacional, dotadas de órgãos permanentes, próprios e independentes, encarregados de gerir interesses coletivos e capazes de expressar uma vontade juridicamente distinta de seus membros" (SEITENFUS, 1997, p. 26-27). Com um número crescente e difícil de precisar, essas sociedades adquirem destaque em âmbito internacional, uma vez que tratam das mais diversas temáticas - alguns exemplos das áreas são manutenção da paz, segurança, saúde, finanças, comércio e integração regional.

Ao buscar interesses comuns e promover a cooperação entre os membros, essas entidades direcionam e atuam como mediadoras nas relações entre os países. Responsáveis pelo gerenciamento de recursos monetários e técnicos, pela produção de informações sobre diversas áreas de políticas públicas e dotadas de autoridade, elas possuem a capacidade de alterar o comportamento dos Estados (GONNET, 2012).

Dessa forma, é fundamental discutir o impacto das instituições internacionais em âmbito interno, nas políticas públicas dos países, sejam membros ou não. Pretendese, neste artigo, demonstrar, a partir das teorias de transferência e difusão, como as organizações internacionais podem condicionar as políticas públicas dos países. Para isso, foi feita uma revisão de literatura de transferência e difusão de políticas públicas ${ }^{2}$ com enfoque no papel dessas instituições. Aliado a isso, foram levantados estudos de caso envolvendo a Organização das Nações Unidas (ONU), o Banco Mundial, a União Europeia (UE) e o Mercado Comum do Sul (Mercosul).

2 A literatura aponta diferença entre os termos difusão e transferência de políticas públicas. A difusão traria uma perspectiva geral para a adoção de políticas públicas, incluindo todos os possíveis canais de influência, conforme Knill (2005). A transferência diz respeito aos processos bilaterais, ou seja, de um contexto para outro, seguindo a explicação de Dolowitz e Marsh (1996). Neste artigo, será analisado como as organizações internacionais, de um modo geral, podem condicionar ambos os processos. 
Os elementos encontrados na análise das organizações mencionadas indicam que essas instituições podem ser entendidas como agentes de transferência e difusão de políticas públicas, condicionando as dos países, sejam eles membros ou não. Assim como podem estar relacionadas com a razão para o engajamento no processo, podem, também, determinar o grau de transferência ou, ainda, figurar como atores ou origem.

Para trazer essa discussão, o presente artigo foi dividido em duas partes. A primeira discute, a partir da literatura de Relações Internacionais e transferência e difusão de políticas públicas, como as organizações internacionais podem ser agentes nesse processo. A segunda parte apresenta, com base em documentos ou estudos acerca das organizações selecionadas, casos em que essa capacidade de condicionar as políticas públicas dos países é confirmada, a saber: i) a difusão da Convenção sobre os Direitos das Pessoas com Deficiência por parte da ONU; ii) a atuação do Banco Mundial na promoção de boas práticas e em conjunto com comunidades epistêmicas, o que propicia um ambiente para os processos de transferência e difusão de políticas públicas; iii) os esforços da UE na difusão de seu modelo de governança e integração; iv) as transferências de política nas áreas de educação, saúde e políticas migratórias no Mercosul.

\section{Como as organizações internacionais podem impactar as políticas públicas?}

Para entrar nessa discussão sobre as organizações internacionais e como elas podem impactar as políticas públicas, devem ser retomadas algumas premissas da perspectiva de regimes internacionais e do institucionalismo ${ }^{3}$, que apontam as tendências para expectativas e de cooperação entre Estados, assim como a busca de interesses comuns por parte dessas instituições. Em seguida, será discutido como essas organizações podem ser agentes de transferência e difusão de políticas públicas.

Regimes internacionais podem ser definidos como "princípios, normas, regras e procedimentos de tomada de decisões de determinada área das relações internacionais

\footnotetext{
${ }^{3}$ As teorias de Relações Internacionais podem ser classificadas em três grandes vertentes: realismo, liberalismo e construtivismo. Dentro do liberalismo, está a vertente institucionalista (WALT, 1998).

O institucionalismo pressupõe que, quando os Estados podem beneficiar-se mutuamente da cooperação, os governos tendem a construir instituições. Estas podem prover informações, reduzir custos de transação, tornar acordos mais confiáveis, estabelecer pontos focais para operação e, em geral, facilitar a operação na reciprocidade. Elas desempenhariam um papel fundamental, uma vez que controlam efeitos de poder e interesses, o que justifica sua existência (KEOHANE; MARTIN, 1995, p. 42).
} 
em torno dos quais convergem as expectativas dos atores” (KRASNER, 2012, p. 93). Em outras palavras, esperam-se um padrão comportamental com base em questões morais, direitos e obrigações assumidos, prescrições de ação ou práticas para a execução das decisões comuns entre os atores. 0 autor divide essa relação entre regimes e comportamento dos Estados em três vertentes: i) não haveria qualquer relação entre regimes e comportamentos; ii) os regimes determinariam o comportamento dos Estados sob circunstâncias específicas; iii) estariam completamente interligados, ou seja, os regimes condicionariam o comportamento dos Estados.

Para este estudo, os entendimentos possíveis são de que haveria um condicionamento total ou sob circunstâncias específicas, ou seja, regimes internacionais e comportamento dos Estados estão relacionados. É o alinhamento entre os atores e a convergência de expectativas e de comportamento que propiciam a cooperação e o investimento em instituições internacionais.

Quando a cooperação pode trazer benefícios mútuos aos Estados, estes tendem a construir instituições. Estas podem prover informações, reduzir custos de transação, tornar acordos mais confiáveis, estabelecer pontos focais para operação e, em geral, facilitar a operação na reciprocidade. Elas também têm um efeito interativo, uma vez que os resultados variam de acordo com poder e interesses (KEOHANE; MARTIN, 1995).

Um dos principais papéis das instituições está ligado ao provimento de informações. Quanto mais segura forem estas, maior a tendência em seguir políticas que podem maximizar a utilidade e cooperar. Embora as instituições não representem o único mecanismo possível de coordenação, em situações de complexidade devido ao número de atores, elas podem trabalhar pontos focais que tornam particulares os resultados proeminentes. Dessa forma, podem mitigar o medo de ganhos diferenciados, o que torna possível a cooperação (KEOHANE; MARTIN, 1995).

Essas instituições podem ser um fator para a transferência e a difusão de políticas públicas. Trata-se de "processos em que o conhecimento sobre políticas, arranjos administrativos, instituições de um período e/ou lugar são usados no desenvolvimento de políticas, arranjos administrativos e instituições de outro período e/ou lugar" (DOLOWITZ; MARSH, 1996, p. 344).

Para entender os elementos envolvidos no processo de transferência de política pública, Dolowitz e Marsh $(1996,2000)$ fazem uma revisão de literatura sobre 
transferência de políticas públicas e, a partir disso, elaboram um quadro conceitual envolvendo os seguintes aspectos: razão, atores envolvidos, componentes transferidos, origem, graus de transferência, restrições e demonstração do processo de transferência. É importante descrevê-los para entender como estão relacionados com a ação das organizações internacionais.

Dentre os aspectos elencados pelos autores para entender a razão, é explicado que esse pode ser um processo voluntário ou coercitivo. No caso do voluntário, busca-se uma solução para determinada questão e/ou problema oriundo da insatisfação com o status quo. No caso do coercitivo, pode ser direto ou indireto. Enquanto o primeiro diz respeito a situações em que um governo ou uma organização internacional impõe sobre outro/a determinada política/ação, o segundo está ligado às externalidades e à interdependência entre os países. Esses processos não podem ser considerados estanques, pois essas classificações podem envolver mais de um elemento ou, ainda, mudar de acordo com a negociação4 . (DOLOWITZ; MARSH, 1996, 2000).

Nesse sentido, ao aplicar essa questão a como as organizações internacionais podem ser agentes de transferência e difusão de políticas públicas, observa-se que elas podem não só determinar a adoção de uma política, como nos casos em que o Banco Mundial delimita condições para empréstimos, mas também condicionar os países na busca de soluções para determinados problemas comuns, através da difusão de boas práticas. Assim sendo, ao mesmo tempo em que há uma adesão por questões coercitivas a alguns elementos, pode haver voluntariedade para outros.

A respeito dos atores envolvidos no processo, Dolowitz e Marsh (1996, 2000) elencam uma série de categorias, que podem atuar individualmente ou em conjunto: funcionários, políticos eleitos, grupos de pressão, burocratas, empresários de política e especialistas, corporações transnacionais, instituições supranacionais e consultores governamentais e não governamentais. Para este trabalho, é importante compreender o

4 Há que ser mencionado que parece ser contraditório o fato de as organizações internacionais serem associações voluntárias entre Estados e poderem impor uma política. Entretanto, isso pode ocorrer dependendo das características da instituição e do relacionamento.

Por exemplo, numa organização com caráter supranacional, as políticas são definidas por seus órgãos decisores, que são mais independentes em relação aos países, e impostas aos membros, como será visto no caso da UE sobre o euro, em que há um sacrifício da autonomia nacional para reduzir os custos da divergência.

Outra ilustração seria o relacionamento com uma instituição financeira internacional. Normalmente ela impõe suas condições para o empréstimo e trabalha para que os objetivos do projeto sejam atendidos do modo como ela demandou, como será observado no caso do Banco Mundial. 
papel dessas duas últimas categorias, que também são enfatizadas pelos atores. As instituições internacionais e os consultores - conhecidos também como comunidades epistêmicas - colaborariam na formação de um consenso internacional sobre determinado problema, bem como na possível solução.

Quanto aos componentes transferidos, podem ser política - ou seja, meta, conteúdo e instrumentos -, programas ou lições negativas, de acordo com Dolowitz e Marsh $(1996,2000)$. Em relação à origem da transferência, pode acontecer nos/entre os seguintes níveis internacional, nacional e local. Além disso, experiências passadas podem ser consideradas na tomada de decisão. Assim, da mesma forma que uma organização internacional pode ser a origem de um modelo de política, ela pode colaborar na difusão de outros governos/organizações através das boas práticas.

No que se refere aos graus de transferência, os autores mencionados estabelecem os seguintes: cópia, emulação, mistura ou inspiração. A cópia é a implantação de uma política tal qual sua origem. A emulação diz respeito à transferência dos princípios e ideais do modelo em questão. A mistura ou síntese é o processo em que há a combinação de determinada política a elementos de outra. A inspiração é a busca e o conhecimento, para a solução de questões locais, de outros modelos. Talvez, nesse sentido, o que diferencie a emulação da inspiração é que na última o resultado final pode ser diferente do original.

Em se tratando das restrições ao processo de transferência, ou seja, os fatores que podem determinar o sucesso ou não da relação, Dolowitz e Marsh (1996, 2000) apontam que estão as questões de complexidade (advindas de jornais, revistas, televisão e rádio), políticas anteriores, fragilidade estrutural (ligadas a ideologias, proximidade cultural, tecnologia, economia e burocracia) e a língua. Dificilmente os contextos - tanto do "doador" como do "receptor" - possuiriam as mesmas condições. Dessa maneira, esses são alguns dos fatores que devem ser considerados nesse tipo de estudo.

Para demonstrar que houve esse tipo de relação, Dolowitz e Marsh $(1996,2000)$ recomendam a análise de declarações, mídias, conferências, relatórios. No caso das organizações internacionais, as atas de reunião da área de interesse se mostram profícuas na identificação de qual foi o processo, como ele se deu e quem o protagonizou.

Descritos os elementos envolvidos no processo de transferência e difusão de 
políticas públicas, convém trazer aspectos apontados no trabalho seguinte dos autores. Posteriormente, em resposta a algumas críticas recebidas, reconhecem que o estudo da transferência de políticas vem de áreas correlacionadas ao seu trabalho e que estas contribuíram na construção de definição e enquadramento. Eles defendem sua tese, destacando que há muitas menções à definição por eles utilizada em bases de dados internacionais ${ }^{5}$; reforçam, inclusive, que as críticas à área partem do trabalho deles. Além disso, esclarecem que o quadro conceitual, apresentado neste texto anteriormente, foi elaborado como uma heurística, devendo, portanto, ser trabalhado e/ou melhorado por aqueles que o usam, uma vez que não se trata de um modelo normativo (DOLOWITZ; MARSH, 2012).

Para os autores, o início do processo de transferência - por jurisdições, organizações internacionais, entre outros - acontece com o objetivo de resolução de questão/problema. Entretanto, o decorrer do processo depende de outros fatores relacionados ao ambiente e à tomada de decisão que não estão necessariamente ligados àquele que iniciou o processo.

Ao considerar o ciclo de política, reconhece-se que outros atores e instituições com seus respectivos conhecimentos, interesses e motivações - poderão ter envolvimento nesse processo. Por isso, entender quando e como isso acontece pode fornecer informações sobre as motivações - o que vem, de onde vem, em que será utilizado - do engajamento. Dolowitz e Marsh (2012) também apontam que a área de transferência e difusão de políticas públicas envolve uma variedade de ferramentas teóricas, enfatizando a discussão a respeito do conceito e dos modos de governança. Eles argumentam que, dependendo do modo de governança - hierarquia, mercado ou redes -, a natureza e o papel da transferência de políticas públicas podem ser diferentes. A partir desse exemplo, reforçam a necessidade de inserção dessas discussões sobre transferência e difusão nesses debates teóricos mais amplos.

Por essa perspectiva, este artigo propõe o debate dentro da área de Relações Internacionais, tendo em vista que as organizações internacionais podem ser classificadas como atores e/ou origem no processo de transferência e difusão de políticas públicas. Alguns autores (DOLOWITZ; MARSH, 2000; GONNET, 2012; STONE,

5 Em uma consulta, em 27/6/2016, à plataforma Google Acadêmico, verifica-se que o trabalho de Dolowtiz e Marsh de 1996 foi citado por 1.761. Já o de 2000 foi citado por 2.144. É por essa amplitude que se optou pelos autores como referencial teórico para o estudo em tela. 
2001, 2004) dedicam especial atenção a essa categoria, dada a complexidade dos fatores envolvidos, seja pela autoridade que possuem, pelos recursos que gerenciam, pela promoção das boas práticas. Esse processo pode ocorrer entre as organizações internacionais e algum país - membro delas ou não -, ou até mesmo entre as instituições.

Stone $(2001,2004)$ destaca as organizações internacionais como atores de transferência e difusão de políticas, tendo em vista que estas podem ser meios de desenvolvimento de políticas setoriais comuns. A autora defende, também, que regimes internacionais podem levar a uma harmonização de políticas. Entende-se que da mesma forma acontece com as instituições em tela. 0 Mercosul, por exemplo, criado pelo Tratado de Assunção, em 1991, traz a previsão, no seu art. 1ํㅡ, do compromisso da harmonização de legislação, para o fortalecimento da integração, entre os Estadospartes, de áreas pertinentes.

Dolowitz e Marsh (2000) explicam que essas instituições propiciam um espaço de observação e troca de experiências das práticas e políticas entre os membros, um ambiente propício para transferência e difusão entre os atores, uma vez que se pode observar ações de sucesso e/ou de insucesso já implantadas por outras jurisdições. Além disso, também podem ser responsáveis por iniciar esses processos, quer de modo coercitivo, através de suas políticas ou condições, quer de modo voluntário, por meio de suas conferências, relatórios e recomendações.

Gonnet (2012), além de explicitar a autoridade dessas organizações, chama a atenção para a gestão de recursos técnicos e monetários pelos quais são responsáveis. Desse modo, podem produzir informações a respeito de políticas públicas das mais diversas áreas, considerando a capacidade de articulação e mediação da construção de interesses dos atores e atividades sociais e o recrutamento de corpo técnico para mapear, elaborar propostas e direcionar as soluções para as políticas governamentais. Outro aspecto fundamental é que, dentro da jurisdição e em relação à opinião pública, as instituições colaboram para a legitimação de processos e políticas.

Ficam evidenciadas, portanto, as várias formas pelas quais as organizações internacionais podem atuar como agentes de transferência e difusão de políticas públicas: promovendo o engajamento no processo - o que está relacionado com o grau de transferência -, figurando como ator, sendo a origem da política, dentre outras. 
Conforme afirma Pereira (2015, p. 2), ao tratar da aplicação dos estudos de transferência e difusão de políticas públicas aos blocos regionais, essas instituições “seriam espaços importantes de disseminação de normas, de ideias e de novos desenhos de políticas públicas setoriais destinadas ao enfrentamento de uma variedade de problemas complexos da agenda dos Estados nacionais”. Essa afirmação pode ser aplicada de modo geral às organizações internacionais. Para evidenciar o que foi defendido na primeira seção deste trabalho, na próxima serão apresentados alguns exemplos práticos dessa atuação.

\section{A transferência de políticas pelas organizações internacionais na prática}

Para demonstrar como essas instituições agem como atores de transferência e difusão de políticas públicas, serão analisadas - a partir de documentos institucionais e/ou artigos científicos - quatro organizações internacionais diferentes em termos de abrangência e finalidade: ONU, Banco Mundial, UE e Mercosul. Com isso, poderão ser identificados elementos que comprovem a capacidade de transferir e/ou disseminar políticas ou explicitem algum caso concreto.

ONU

A Organização das Nações Unidas foi fundada em 1945, no período pós-Segunda Guerra Mundial, com o objetivo de manter a paz e a segurança internacionais, desenvolver relações amistosas entre as nações, cooperar internacionalmente para a resolução de problemas internacionais econômicos, sociais, culturais ou humanitários, bem como ser um centro com a finalidade de harmonização de ação das nações, conforme sua carta, promulgada no Brasil (1945) por meio de decreto.

Considerando que um dos propósitos da carta da ONU é a harmonização de ação das nações e dada a diversidade de temáticas trabalhadas, acredita-se que a organização ilustra a questão elencada pela teoria a respeito dos espaços de observação e troca de experiência entre os membros. Entretanto, o exemplo mais simbólico são os princípios fundamentais dos direitos humanos. Proclamada pela Assembleia Geral das Nações Unidas em 1948, a Declaração Universal dos Direitos Humanos (DUDH) adquiriu uma força de lei no mundo inteiro e chega a ser considerada por alguns juristas como jus cogens. 
Jus cogens é expressão utilizada para tratar daqueles direitos classificados como imperativos, ou seja, aqueles que trazem conteúdo essencial. Essa previsão advém da Convenção de Viena sobre o direito dos tratados, a qual define esse termo como norma aceita/reconhecida pela comunidade internacional. Ao elencar exemplos de normas dessa magnitude, o autor afirma que estão os princípios fundamentais dos direitos humanos (NASSER, 2005).

Rezek (2001, p. 146) diz que esse seria "o conjunto de normas que, no plano do direito das gentes, impõem-se objetivamente aos Estados (...)". Em seguida, traz os artigos 53 e 54 da Convenção de Viena, que versam sobre essa norma imperativa e enfatizam a nulidade do tratado que entrar em conflito com essa regra, dado que esta é aceita e reconhecida pela sociedade internacional como algo que não se pode derrogar e que só pode ser alterada por outra da mesma natureza. Nesse contexto, a carta da ONU e a DUDH representam a base de princípios e ideias a partir da qual países copiam, emulam, combinam e inspiram seus modelos de políticas para esse setor. Elas representam a base das legislações dos países e mesmo de outros tratados.

A Convenção sobre os Direitos das Pessoas com Deficiência é um desses documentos que se inspiram em ambos os documentos da ONU, o que é mencionado, inclusive, no seu preâmbulo. Tal convenção foi ratificada e encontra-se em vigência no Brasil por meio do Decreto Legislativo no 186, de 9 de julho de 2008, e do Decreto no 6.949, de 25 de agosto de 2009, com força de emenda constitucional (CONVENÇão SOBRE OS DIREITOS DAS PESSOAS COM DEFICIÊNCIA, 2011). No caso do Brasil, a incorporação das normas de direitos humanos está prevista na Constituição federal, em seu art. $5^{\circ}$, que estabelece o rito necessário para aprovação de tais normas com a força de emendas e, além disso, determina a aplicação imediata das normas de direitos a garantias fundamentais (BRASIL, 1988).

A menção ao exemplo brasileiro pode levantar a crítica a respeito de que se trata apenas da incorporação de tratados ao seu ordenamento jurídico. Entretanto, deve-se observar que, assim como acontece em relação a esse país, outros signatários do documento também levaram as obrigações pactuadas ao âmbito doméstico. Mais do que internalizar um compromisso assumido internacionalmente, não poderia ser esse um exemplo de transferência e difusão de políticas?

É importante retomar alguns apontamentos teóricos para responder a esse 
questionamento. Os processos de transferência e difusão de políticas públicas, conforme Dolowtiz e Marsh (2000), podem ser oriundos de uma organização internacional e o componente transferido pode ser o conteúdo de determinada política. Uma possível razão para adesão ao processo são as pressões internacionais (imagem, consenso, percepções).

Dessa forma, ao contrário da DUDH, que representa uma norma imperativa, a Convenção sobre os Direitos das Pessoas com Deficiência é um documento cuja adesão é voluntária. Seguindo a lógica teórica, não estaria a ONU difundindo um modelo que servirá de base para a política pública de vários países?

\section{Banco Mundial}

O Banco Mundial foi fundado em 1944, visando à reconstrução no período pósguerras. Esse continua a ser um de seus propósitos institucionais, em conjunto com a redução da pobreza por meio de uma globalização inclusiva e sustentável. Contando atualmente com 189 membros, suas metas até 2030 são acabar com a extrema pobreza e promover a prosperidade compartilhada. Aliás, são essas características que o diferenciam de um banco comum. Trata-se de uma fonte de assistência financeira e técnica para países em desenvolvimento, cujas áreas de investimento são: a educação, a saúde, a administração pública, a infraestrutura, o desenvolvimento do setor financeiro e privado, a agricultura e a gestão de recursos naturais e ambientais. 0 trabalho realizado compreende assessoria política, análise e pesquisa e assistência técnica. Uma das formas de apoio é o fomento para participação em conferências e fóruns sobre a temática de desenvolvimento, realizado em colaboração com parceiros (WORLD BANK, 2016a, 2016b, 2016c).

O Banco Mundial pode ser considerado ator de destaque no quesito transferência e difusão de políticas públicas. Silva (2015) faz um estudo com a finalidade de analisar as prescrições e diretivas do Banco Central a respeito de temas relativos ao enfrentamento da pobreza e à influência na formulação de políticas públicas do tipo CCT (Conditional Credit Transfer) na América Latina e no Caribe. Nesse tipo de procedimento, identificou-se que houve a transferência de concessões e ideias, assim como de arranjos institucionais e políticos. Para a autora, 
a difusão de ideias provenientes das OIs e IFIs, e, no caso da pesquisa, do Banco Mundial, interferiu no processo de tomada de decisão dos governos locais a respeito das políticas de enfrentamento da pobreza a serem adotadas, fomentando um processo de modelagem de políticas públicas, que provocou a adoção, nas duas últimas décadas, de trinta e seis exemplos de políticas com grande similaridade institucional, ainda que em países com profundas disparidades em suas trajetórias políticas, sociais, culturais e econômicas (SILVA, 2015, p. 132).

Fica evidente, a partir desse trabalho, a capacidade do Banco Mundial de condicionar as políticas públicas dos países com os quais possui relacionamento. Ao mesmo tempo em que impõe condições contratuais aos clientes, a instituição também difunde políticas através de boas práticas, apresentadas em conferências e fóruns, nos quais é incentivada a participação, conforme a descrição dos serviços em seu sítio eletrônico.

Outra forma de atuação é por meio de comunidades epistêmicas, conforme traz De Sá Guimarães (2012) ao analisar a burocracia do Banco Mundial. Não há apenas a atuação desses grupos internamente, mas também em relações com a sociedade civil, influenciando a opinião pública nas políticas de sua preferência. Essa abertura estaria relacionada à visão de maior eficiência nos programas com a participação desses grupos e à pressão devido a desastres ambientais e sociais oriundos de projetos em desenvolvimento, no período entre 1980 e 1990. Desse modo, o objetivo não era apenas escutar a sociedade civil, mas também cooptá-la. 0 modelo de recrutamento adotado com a reforma propiciou a criação de subcomunidades epistêmicas dentro do órgão, o que colaboraria na interface com as organizações não governamentais. Assim, haveria uma atuação conjunta para atender aos objetivos dos projetos e do banco, uma vez que o terceiro setor também teria responsabilidade nas políticas desenvolvidas pelo Banco Mundial.

Essas atuações do Banco Mundial são discutidas em Stone (2004). Segundo a autora, algumas organizações internacionais possuem setores responsáveis por pesquisa, desenvolvimento e consultorias, de modo a validar seus objetivos cientificamente e promover a educação e a conscientização pública. 0 compartilhamento de conhecimento constitui uma de suas principais ferramentas de desenvolvimento econômico e institucional.

0 trabalho com as comunidades epistêmicas, os grupos de pressão, a promoção das boas práticas e o compartilhamento de conhecimento demonstram a capacidade da 
organização internacional em condicionar os projetos de políticas dos países. São diferentes categorias de atores e razões combinadas nesses processos de transferência e difusão de políticas.

\section{União Europeia}

A origem da União Europeia é datada de 1951, com a cooperação econômica denominada Comunidade Europeia do Carvão e do Aço (Ceca), entre a Bélgica, a Alemanha, a França, a Itália, Luxemburgo e os Países Baixos. O projeto, que começa a unir política e economicamente os países europeus com a finalidade também de assegurar a paz, cresceu a atualmente conta com 28 Estados-membros ${ }^{6}$ (UNIÃO EUROPEIA, 2016a).

Ginsberg (2007) afirma que, em termos de política externa e de segurança, no início, o bloco europeu possuía um fórum intergovernamental fraco e que, ao longo do tempo, tornou-se mais institucionalizado e atrelado a outras demandas da integração europeia. Dada a variedade de elementos institucionais, trata-se de um processo que pode variar de negociação intergovernamental para relação transgovernamental com implantação supranacional. Segundo o autor, esse crescimento afeta diretamente a cooperação, mesmo em domínios como esse, assim como o impacto e a influência da UE na política mundial.

O bloco não condicionaria apenas as políticas de seus membros, mas também as de outros países que não pertencem ele. Nesse sentido, três exemplos podem ser mencionados: o primeiro é a harmonização de políticas monetárias e econômicas; o segundo é o estabelecimento de missões de acompanhamento do Estado de direito e de fronteiras como parte da política externa; o terceiro é a realização de esforços contínuos para a exportação do seu modelo de integração regional.

A adoção do euro demonstra o esforço do bloco regional pela harmonização de políticas monetárias e econômicas. Para Stone (2004), esse processo ganhou força pelo reconhecimento da interdependência entre os Estados, assim como pelos benefícios da adesão por meio de incentivos econômicos e políticos, apesar de sacrifícios da autonomia nacional contraporem os custos de divergência.

6 Deve-se mencionar que o Reino Unido, em referendo popular no dia 23/6/2016, optou por sair da UE. Como o país ainda não acionou a cláusula para se retirar do bloco, a qual está prevista em tratado, as normas entre as partes continuam válidas e não haverá um vácuo legal. 0 processo será negociado entre as partes (UNIÃO EUROPEIA, 2016b). 
As ações de política externa de segurança e defesa (Pesd) também compreendem missões que podem colaborar com o processo de transferência e difusão de políticas públicas. Ginsberg (2007) descreve duas missões com a finalidade de prestação de assistência da União Europeia a países que necessitam estabelecer sistemas judiciários independentes: República da Geórgia, em 2004, com o objetivo de auxiliar o governo na reforma - e melhora - dos sistemas de justiça e aplicação penal, e Iraque, em 2005, voltada à formação de juízes, policiais e agentes penitenciários que atuariam na gestão do sistema criminal. Ao mesmo tempo em que essas atividades colaboram com a estruturação de um sistema, elas também difundem normas, valores, medidas administrativas e políticas dos países europeus àqueles que são auxiliados.

De um modo geral, há uma realização de esforços para a difusão de sua expertise de cooperação, governança e integração regional. A tendência é de continuidade da exportação desses mecanismos, quer por meios institucionais, quer por seu poder de atração (GINSBERG, 2007). Nessa perspectiva, a ilustração dessa questão pode ser feita pela Declaração de Bolonha (1999), em que os membros declaram que a eficiência e a vitalidade de uma nação podem ser medidas pelo grau de fascínio que ela exerce sobre outras e que almejam que seu sistema de ensino atinja um grau de atração como suas tradições o fizeram.

\section{Mercosul}

O Mercado Comum do Sul foi estabelecido em 1991 por Argentina, Brasil, Paraguai e Uruguai ${ }^{7}$. As implicações previstas no art. 1ำ do seu tratado constitutivo fazem referência à livre circulação de bens, serviços e fatores produtivos, ao estabelecimento de tarifa externa e adoção de política comercial comuns a terceiros, à coordenação de políticas macroeconômicas e setoriais entre os membros e, conforme já mencionado no texto, à harmonização na legislação entre os membros para o fortalecimento da integração regional (TRATADO DE ASSUNÇÃO, 1991).

Alguns estudos têm sido feitos a respeito dos processos de transferência e difusão de políticas públicas no bloco regional, em especial nas áreas relativas a educação superior, formação de recursos humanos na área de saúde e políticas migratórias (BERNARDO, 2015; CULPI, 2015; PEREIRA, 2015).

7 Atualmente, são considerados Estados-partes do Mercosul a Argentina, o Brasil, o Paraguai, o Uruguai e a Venezuela; a Bolívia encontra-se em processo de adesão. São classificados como Estados associados o Chile, o Peru, a Colômbia, o Equador, a Guiana e Suriname (Mercosul, 2016). 
$\mathrm{Na}$ área educacional, Bernardo (2015), a partir da análise dos documentos acordos e atas de reuniões de ministros da Educação dos países-membros e da comissão - relativos ao ensino superior do bloco, aponta que os fóruns educacionais propiciam esse espaço de troca, combinação e difusão de políticas. Nesse aspecto, indica um protagonismo nas discussões, encaminhamentos de propostas e elaboração de programas por parte da Argentina e do Brasil. Apenas para ilustrar um protagonismo de cada membro mencionado, a Argentina destaca-se na proposição e coordenação do Núcleo de Estudos e Pesquisa em Educação Superior; o Brasil tem uma atuação forte em relação à proposição e condução da mobilidade de professores, com o Marca Mobilidade Docente. Ambas as iniciativas estão vigentes e condicionam as políticas dos Estados-partes, o que demonstra que o bloco funciona como um espaço de síntese e disseminação de políticas públicas. Ainda, exemplifica o que Dolowitz e Marsh (2000) tratam como dualidade dos termos "doador" e "receptor" de políticas, pois, dentro da mesma área, os países podem desempenhar diferentes papéis; ao mesmo tempo em que um país protagoniza uma temática, ele acata a proposta de outro em um tópico diferente.

Culpi (2015) promove o debate de transferência e difusão em âmbito mercossulino sobre as políticas migratórias. Partindo do pressuposto de que o bloco regional se demonstra relevante a esse processo, a autora analisa os acordos de residência e as políticas de controle e registro dos estrangeiros. Verifica-se um alinhamento de ideias entre Argentina e Brasil a respeito da migração como direito humano, mas diferenças significativas na implantação. Chama a atenção o papel desempenhado pela Argentina na apresentação de conteúdos de políticas migratórias, que encontram no Foro Especializado Migratório do Mercosul e nos subgrupos de trabalho do Grupo Mercado Comum um meio de difusão, o qual propicia emulações, sínteses e inspirações. Dessa forma, o bloco regional destaca-se no processo de difusão de políticas entre os membros.

A formação de recursos humanos na área de saúde é abordada por Pereira (2015). Com o objetivo de examinar os esforços de harmonização de políticas de saúde, a partir do Subgrupo de Trabalho 11 - Saúde, do Grupo Mercado Comum, o autor estuda o tratamento da formação de recursos humanos e o exercício profissional nas reuniões do fórum em tela. Para ele, a pauta é relevante, pois envolve as questões relativas à livre 
circulação de pessoas e as dificuldades em relação à operacionalização das decisões no bloco e nos membros. Essa é uma discussão que está atrelada à implantação do Mecanismo Experimental de Acreditação de Cursos para o Reconhecimento de Títulos de Grau Universitário na área de Medicina, tendo em vista o reconhecimento dos diplomas nos Estados-partes que seria propiciado. Entretanto, o instrumento torna possível a mensuração da qualidade, mas não viabiliza o exercício da profissão em outro mercado de trabalho, dada a necessidade de revalidação. É nesse sentido o debate proposto no subgrupo: reconhece-se a necessidade de harmonização de programas e normas para assistência à saúde e de padronização das regras referentes ao exercício da profissão, assim como de critérios similares referentes à formação e ao registro profissionais. Embora a discussão tenha sido internalizada pelos países, a implantação dos temas de controle e registro ainda deixa a desejar, considerando a imperatividade da revalidação. Nesse âmbito, há que se ter consciência da atuação organizada por parte de profissionais com a finalidade de influenciar a discussão e proposições acerca das decisões do Grupo Mercado Comum. Sobre esse contexto, o autor esclarece que o Brasil incorporou o trabalho desenvolvido pelo fórum, chegando, inclusive, a estabelecer um espaço interno para participação da sociedade civil, das associações profissionais e de representantes do Estado, na tentativa de encontrar alternativas aos problemas enfrentados. Ele afirma que os "resultados não acontecem no ritmo esperado, mas não são pouco significativos, considerando a resistência das associações profissionais a essa livre circulação".

Enfim, esses exemplos mercossulinos demonstram a questão apontada pela teoria de que as organizações internacionais funcionam como um espaço de troca e observação dos sucessos e insucessos das políticas dos países-membros e, consequentemente, de combinações, sínteses e inspiração de políticas públicas. Apontam também as negociações envolvidas na harmonização de legislação entre os membros, que facilita o processo de transferência e difusão de políticas públicas. Outro ponto interessante é, no caso da saúde, a atuação de grupos organizados, representando o que se conhece por comunidades de especialistas ou comunidades epistêmicas, ou seja, um corpo técnico com o interesse e a capacidade de mapear problemas, elaborar soluções e condicionar políticas.

Ao fazer uma análise da integração mercossulina, Vingevani e Ramanzini (2014) 
apontam a defesa da autonomia por parte do Brasil, o que estaria alinhado com a intergovernamentalidade do bloco e não adensamento das instituições do bloco. Talvez por isso a análise pela vertente de transferência e difusão de políticas públicas seja interessante nesse caso. Num modelo intergovernamental e em que se defende a autonomia, é de se esperar que a instituição não tenha características de impor políticas, mas de propiciar trocas e experiências entre seus membros.

\section{Considerações finais}

Considera-se que o objetivo deste trabalho, de demonstrar como as organizações internacionais podem influenciar as políticas públicas dos países, foi atingido teórica e empiricamente. Na primeira parte, foram retomados estudos que apontam para essa capacidade de tais instituições; na segunda parte, a partir da análise de quatro organizações, os exemplos confirmaram essa característica.

Do ponto de vista teórico, identificou-se, a partir das teorias de transferência e difusão de políticas públicas, que as organizações internacionais podem condicionar as políticas dos países - membros delas ou não - de diversas maneiras: ao determinarem ou promoverem o engajamento no processo, ao serem atores/protagonistas, ao fornecerem o modelo e/ou a política a serem transferidos, entre outros.

Os apontamentos teóricos foram confirmados pelo levantamento de estudos sobre documentos e ações de quatro organizações internacionais: i) ONU: a Declaração Universal dos Direitos Humanos e outras relativas à temática funcionam como direito imperativo e princípio de políticas públicas dos países. Esses documentos foram a base para a política brasileira para pessoas com deficiência, vigente com força de emenda constitucional; ii) Banco Mundial: além de impor suas políticas a países com os quais possui contrato, atua como receptor e difusor de boas práticas e por meio de comunidades epistêmicas e grupos de pressão para lograr os objetivos previstos em seus projetos; iii) União Europeia: o esforço da política externa da UE para exportação de seus modelos de governança e integração dentro (caso da adoção do euro) e fora do bloco (missões de acompanhamento do Estado de direito e de fronteiras); e iv) Mercosul: tendo como ponto de partida a análise dos fóruns de saúde, educação e migração, verifica-se que o bloco funciona como espaço de síntese e disseminação de políticas públicas. 


\section{Referências}

BRASIL. Constituição (1988). Constituição da República Federativa do Brasil. Brasília, DF: Senado Federal: Centro Gráfico, 1988.

DECRETO № 19.841, DE 22 DE OUTUBRO DE 1945, que promulga a Carta das Nações Unidas, da qual faz parte integrante o anexo Estatuto da Corte Internacional de Justiça, assinada em São Francisco, a 26 de junho de 1945, por ocasião da Conferência de Organização Internacional das Nações Unidas. 1945. Disponível em: < http://www.planalto.gov.br/ccivil_03/decreto/1930-1949/d19841.htm> Acesso em 28 jun 2016.

CONVENÇÃO SOBRE OS DIREITOS DAS PESSOAS COM DEFICIÊNCIA: Protocolo Facultativo à Convenção sobre os Direitos das Pessoas com Deficiência: Decreto

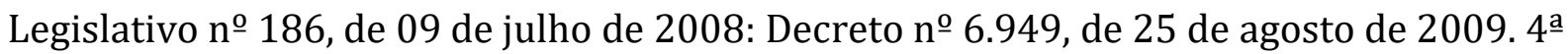
Ed., rev. e atual. Brasília : Secretaria de Direitos Humanos, 2010. 100p.

CULPI, Ludmila A. Mercosul e políticas de migração: análise do processo de transferência de políticas públicas migratórias pelas instituições do mercosul (1991-2013). In: Encontro Anual da ANPOCS, 39, Caxambu, Anais, 2015.

DE SÁ GUIMARÃES, Feliciano. A Autonomia Burocrática das Organizações Financeiras Internacionais: Um Estudo Comparado entre o Banco Mundial e o Fundo Monetário Internacional. Contexto Internacional, v. 34, n. 1, p. 255, 2012.

DOLOWITZ, D.; MARSH, D. Learning from abroad: the role of policy transfer in contemporary policy-making. Governance, v. 13, n. 1, p. 5-24, 2000.

. Who Learns What from Whom? A Review of the Policy Transfer Literature. Political Studies, v. 44, p. 343-357, 1996.

2012 .

The future of policy transfer research. Political Studies Review, v. 10, p. 339-345,

GINSBERG, Roy H.; SMITH, Michael E. Understanding the European Union as a global political actor: Theory, practice, and impact. Making History: European Integration and Institutional Change at Fifty, v. 8, p. 267, 2007.

GONNET, Cecilia Osorio. The role of international organizations in a policy diffusion process. Preliminary discussion about the Conditional Cash Transfers programs in Latin America. X Chilean Congress of Political Science (ACCP).Santiago, 2012

KEOHANE, Robert O.; MARTIN, Lisa L. The promise of institutionalist theory. International Security, v. 20, n. 1, p. 39-51, 1995.

KNILL, Christoph. Introduction: cross-national policy convergence: concepts, approaches and explanatory factors. Journal of European Public Policy, v. 12, n. 5, 2005.

KRASNER, Stephen. Causas estruturais e consequências dos regimes internacionais: regimes como variáveis intervenientes. Revista de Sociologia e Política. Curitiba, v. 20, n. 
42, p. 93-110, 2012.

MERCOSUL. Saiba mais sobre o Mercosul. Disponível em <http://www.mercosul.gov.br/saiba-mais-sobre-o-mercosul> Acesso em 29 de jun 2016.

NASSER, Salem Hikmat. JUS COGENS: AINDA ESSE DESCONHECIDO. Revista de Direito FGV, V. 1, N. 2, Jun-Dez, 2005

PEREIRA, Alexsandro Eugênio. Transferência e difusão de políticas públicas no Mercosul: análise da formação de recursos humanos e do exercício profissional na área de saúde (1996-2014). In: Encontro Anual da ANPOCS, 39, Caxambu, Anais, 2015

REZEK, Francisco. Direito Internacional Público: Curso Elementar. São Paulo: Saraiva, 2011.

SEITENFUS, Ricardo A. S. Manual das organizações internacionais. Porto Alegre: Livraria do Advogado, 1997.

SILVA, Evelise Zampier da. Formulações globais e políticas locais: a difusão de políticas de transferência monetária na América Latina e Caribe. 2015. 153 f. Dissertação (Mestrado) - Curso de Programa de Pós-graduação em Gestão Urbana, Pontifícia Universidade Católica, Curitiba, 2015. Disponível em: <http://www.biblioteca.pucpr.br/tede/tde_busca/arquivo.php?codArquivo=3046>. Acesso em: 29 jun. 2016.

STONE, Diane. Transfer agents and global networks in the 'transnationalization' of policy. Journal of European Public Policy. 11:3: 545-566, june, 2004.

. Learning lessons, policy transfer and the international diffusion of policy ideas. CSGR Working Paper n. 69/01. Coventry: The University of Warwick, 2001.

TRATADO DE ASSUNÇÃO. 26 mar. 1991. Disponível em: <http://www.mercosur.int/innovaportal/file/4002/1/tratado_de_asuncion_pt.pdf>. Acesso em: 27 jun. 2016.

UNIÃO EUROPEIA. Declaração de Bologna: de 19 de junho de 1999. Disponível em: < http://www.ehea.info/Uploads/Documents/1999_Bologna_Declaration_Portuguese.pdf > Acesso em: 21 mai 2015.

- Sobre a União Europeia. Disponível em: < http://europa.eu/abouteu/index_pt.htm > Acesso em 28 jun 2016. 2016a.

. Press statement by President Donald Tusk on the outcome of the referendum in the UK. $\quad(24 / 06 / 2016) . . \quad$ Disponível em: http://eeas.europa.eu/delegations/ukraine/press_corner/all_news/news/2016/2016_ 06_24_en.htm > Acesso em 28 jun 2016. 2016b.

UNITED NATIONS. About the UN. Disponível em: < http://www.un.org/en/aboutun/index.html> Acesso em 28 jun 2016. 
—_. Declaração Universal dos Direitos Humanos. 1948. Disponível em: <http://www.un.org/en/universal-declaration-human-rights/index.html > Acesso em 28 jun 2016.

VIGEVANI, Tullo; JÚNIOR, Haroldo Ramanzini. Autonomia, integração regional e política externa brasileira: Mercosul e Unasul. Dados, p. 517-552, 2014.

WALT, Stephen M. International Relations: One World, Many Theories. Foreign Policy, No. 110, Special Edition: Frontiers of Knowledge. Spring, 1998.

WORLD BANK. Organization. Disponível em: <http://www.worldbank.org/en/about/leadership > Acesso em 29 jun 2016. 2016 a.

. What we do. Disponível em: <http://www.worldbank.org/en/about/what-we-do $>$ Acesso em 29 jun 2016. 2016b.

. History. Disponível em: <http://www.worldbank.org/en/about/history > Acesso em 29 jun 2016. 2016b. 